\title{
REVIEW
}

\section{Treatment of gyrodactylid infections in fish}

\author{
Bettina Schelkle1, Andrew P. Shinn ${ }^{2}$, Edmund Peeler ${ }^{3}$, Joanne Cable ${ }^{1, *}$ \\ ${ }^{1}$ School of Biosciences, Cardiff University, Cardiff CF10 3AX, UK \\ ${ }^{2}$ Institute of Aquaculture, University of Stirling, Stirling FK9 4LA, UK \\ ${ }^{3}$ Centre for Environment, Fisheries and Aquaculture Science, Barrack Road, The Nothe, Weymouth, Dorset DT4 8UB, UK
}

\begin{abstract}
Since Norway experienced the devastating Gyrodactylus salaris (Monogenea) epidemics in Atlantic salmon Salmo salar, there has been heightened interest in how to treat gyrodactylosis in fish. Here we summarize chemical treatments previously used against gyrodactylids and discuss the main problems associated with these control measures including efficacy, host toxicity, human health concerns and application of treatments. Unfortunately, for these reasons and because of the different methodologies and different parasite and host species used in previous studies, it is difficult to recommend effective chemotherapeutic treatments. However, we suggest a method for manual removal of gyrodactylids from the host suitable for use in small-scale research facilities.
\end{abstract}

KEY WORDS: Gyrodactylus $\cdot$ Control treatment $\cdot$ Efficacy $\cdot$ Toxicity

Resale or republication not permitted without written consent of the publisher

\section{INTRODUCTION}

A frequently asked, but rarely addressed, question is what is the most effective means of removing Gyrodactylus spp. from their hosts? With increasing interest in this large group of ectoparasitic worms, not only as important pathogens but also as model organisms (reviewed by Bakke et al. 2002, 2007, Cable \& Harris 2002), it seems timely to document the methods that have been used thus far to remove gyrodactylids.

\section{PROBLEMS WITH EXISTING TREATMENTS}

Appendix 1 lists 88 compounds and treatment combinations that have previously been used to treat gyrodactylid infections in research facilities, aquaculture and the hobbyist market. However, selecting the best of these treatments is difficult, because few studies have compared compounds using the same methodologies and the majority of treatments have various associated problems. Formaldehyde, for instance, was found to be $100 \%$ effective at eliminating Gyrodactylus salaris experimentally (Buchmann \& Kristensson 2003), but under large-scale aquaculture conditions it does not eradicate gyrodactylids completely (Rintamäki-Kinnunen \& Valtonen 1996, Rowland et al. 2006), and in some three-spined stickleback Gasterosteus aculeatus populations it is only $10 \%$ effective (J. Cable pers. obs.). Due to its broad anti-parasitic properties, formaldehyde is still commonly used in aquaculture, even though it is classed as a human carcinogen (IARC 2004). Mutagenic and carcinogenic effects are also known for malachite green (Srivastava et al. 2004), which like formaldehyde is widely used as an anti-parasitic treatment, but its effectiveness against Gyrodactylus spp. has not been evaluated. Malachite green is now banned in food fish production in Europe and North America as it is retained in fish flesh (European Council 1990; US Food and Drug Administration and the Canadian Food Inspection Agency, cited in Srivastava et al. 2004).

Alternative treatments include rotenone, an indiscriminate ATPase inhibitor which has been used to control Gyrodactylus salaris in Norway by killing all potential hosts (reviewed in Bakke et al. 2007), including other gill-breathing organisms. This is only partially effective and has potential negative effects on human health. Aqueous aluminium is another alternative that is being tested. However, although aluminium ap- 
peared promising in laboratory studies (Soleng et al. 1999, 2005, Poléo et al. 2004), field trials in Norway using aluminium in combination with rotenone have been problematic because successful treatment of the whole river system requires maintaining a specific concentration without exceeding levels toxic to Atlantic salmon (P. Shave pers. comm.). Aluminium toxicity to fish increases under acidic water conditions (Birchall et al. 1989, Poléo 1995, Soleng et al. 1999), and elevated environmental aluminium levels can result in Alzheimer's disease (Doll 1993) and decreased agricultural and forestry productivity (Bi et al. 2001). Organophosphates, such as trichlorfon, are no longer in use against fish parasites as they cause irreversible effects in nontarget species by phosphorylating acetylcholinesterase (see Kozlovskaya \& Mayer 1984, Peña-Llopis et al. 2003, Costa 2006). Acute and chronic toxicity to other aquatic organisms has also been reported for benzimidazoles (e.g. Oh et al. 2006); however, due to their low efficacy (see Appendix 1), these are not preferred over broad antiparasitic treatments such as formalin.

In addition to efficacy, environmental and human health issues, the main problem associated with current gyrodactylid treatments is their toxicity to the host (Schmahl \& Taraschewski 1987, Santamarina et al. 1991, Tojo et al. 1992, Scholz 1999, Ekanem et al. 2004, Srivastava et al. 2004). Even widely used compounds, such as formaldehyde, may significantly change the host's gill structure and epidermis (Speare et al. 1997, Sanchez et al. 1998, Buchmann et al. 2004). For instance, although zinc exposure initially stimulates host mucus production, mucus is subsequently depleted leaving the fish more susceptible to microbial infections (McGeer et al. 2000). If these fish are subsequently used for experimental infections without a sufficient recovery period, they may show an abnormal response to infection (see review by Bakke et al. 2007). Host respiratory problems are also a common side effect of gyrodactylid treatments due to direct interference with gill function and indirectly via reduction of water quality (e.g. decrease in $\mathrm{pH}$ and/or dissolved oxygen: Smith \& Piper 1972, Ross et al. 1985, Rowland et al. 2006). Toxicity in many cases is dose-dependent, but may also be affected by one or a combination of the following factors: temperature, $\mathrm{pH}$, salinity, mechanism of delivery, species and exposure time (Schmahl \& Taraschewski 1987, Schmahl et al. 1989, Scholz 1999), especially where multiple treatments are used.

Gyrodactylid treatments are applied either orally (with food) or topically (added to the water). Both methods usually lead to application of overly high doses to compensate for lack of control over drug administration (Scholz 1999), which may lead to environmental contamination. Oral administration of some drugs can also reduce host food consumption (e.g. piperazine, Fugotenil ${ }^{\circledR}$ and Neguvon ${ }^{\circledR}$; Tojo \& Santamarina 1998), which increases the dosage needed per unit of food for efficacy. Additionally, compounds that are partially effective as baths may not be effective if administered orally (e.g. trichlorfon; Santamarina et al. 1991, Tojo \& Santamarina 1998). Moreover, resistance of parasites against antihelminthics has been reported, with Goven \& Amend (1982) and Schmahl et al. (1989) finding resistance of gyrodactylids to dimethyl phosphonate and trichlorfon, respectively. Breeding parasite-resistant fish or developing a vaccine against gyrodactylosis would override many of the above problems and bypass the potential issue of drug resistance. Breeding experiments with wild Atlantic salmon Salmo salar that show resistance against Gyrodactylus salaris are currently under way in Norway (R. Salte et al. unpubl.), but we are unaware of any plans for vaccine development. In Norway destocking and drying of fish farms was used successfully to eradicate G. salaris (see Mo 1994); however, this method is not suitable for establishments which receive potentially infected fish on a regular basis and infected fish would still have to be treated.

A major problem with many of the studies presented in Appendix 1 is that they used sub-sampling methods, such as mucus scrapings (e.g. Tojo et al. 1992, Tojo \& Santamarina 1998) or partial examination of fish populations in field trials (e.g. Goven \& Amend 1982). This is a crude and unreliable estimate of parasite infection, particularly where the gyrodactylid is not identified to species level (e.g. Tojo \& Santamarina 1998, Chansue 2007) as different Gyrodactylus spp. show marked site specificities. Furthermore, the majority of compounds trialled successfully have been tested only once. For those with at least 2 independent studies, results have been variable probably because of different methodologies. Hence, many seemingly successful compounds may not be effective when it comes to treating a different host-parasite system. Field studies are of particular importance as they provide an indication of how efficient treatments are on a large scale, potentially for use in the ornamental or food fish industries. However, there have only been a few such studies (see Appendix 1) with only Rach et al. (2000) claiming $100 \%$ efficiency for the compound they tested (hydrogen peroxide). Other authors defined a treatment in the field as successful if it just reduced the pathogen burden (e.g. Lewis 1967, Rintamäki-Kinnunen \& Valtonen 1996).

\section{MANUAL REMOVAL OF GYRODACTYLIDS}

Due to toxicity and/or difficulties in administration (such as the need for prolonged exposure), no treat- 
ment detailed in Table 1 is entirely satisfactory or $100 \%$ effective, although several treatments indicate $100 \%$ efficacy against gyrodactylosis (e.g. formaldehyde and aqueous aluminium). In laboratory trials with small, hardy fish, the most effective means of removing gyrodactylids (at least those that predominantly occur on the skin and fins) is a licensed Home Office procedure in the UK which requires the host to be lightly anaesthetised (using e.g. 0.02\% MS-222, chlorobutanel) whilst the living parasites are removed manually. Following anaesthesia, the fish is transferred to a shallow dish, but kept fully immersed in dechlorinated water and screened using a stereo-microscope with fibre-optic illumination. The latter is essential to prevent the host and parasites overheating during examination on the microscope stage. Parasites can be most easily detected by their movement, but it is still essential to scan all surfaces of the host. Small fish, such as guppies and sticklebacks, can be manipulated using a plastic disposable pipette tip. Once a parasite is detected, the worm can be removed and crushed using watchmaker's forceps. It is essential to ensure that the parasite is not released directly back into the water as even a damaged worm may re-attach to its host and successfully give birth. Once all parasites have been removed, the same screening procedure should be repeated until all fish in a population have been screened clear of parasites on 3 consecutive occasions separated by approximately $1 \mathrm{wk}$, ideally by 2 independent, trained researchers. If a parasite is found on any fish during this process, then the screening process should begin again for the entire host population.

For small fish, such as poeciliids, manual removal of parasites can be effective without any chemical intervention. However, for larger fish (or where gyrodactylids are abundant and/or show a preference for the gills), chemical treatment prior to screening may be the only practical solution to parasite removal. In our laboratories we use levamisole, but this is only available by veterinarian prescription and only reliable if applied to single fish that are closely monitored for signs of toxicity. Screening is still essential to ensure that fish are free of gyrodactylids following chemical treatment, with additional screening on subsequent occasions to ensure the experimental fish are free from infection. For larger fish, such as adult Atlantic salmon Salmo salar, sub-sampling by examining mucus scrapings or selected fins may be the only practical way of screening, but this is not accurate. It is also stressful for the fish as it damages the fish's epithelium, so increasing the risk of secondary infections. An alternative or ideally supplementary procedure to manual removal, but again only suitable for small fish, is to maintain each fish in isolation in a closed system with regular water changes. As fish become immune and gyro- dactylids are shed, there is no opportunity for the parasites to transfer to new hosts. However, even long periods of isolation are not always effective for certain host-parasite combinations (see King et al. 2008) and the accompanying high maintenance is extremely time consuming and costly. Whatever the control method used (chemical, manual or host isolation), thorough screening is essential to ensure parasite extinction. The longer the interval between the 3 consecutive screens the more reliable the procedure. A single (transparent, <1 mm long) gyrodactylid missed in an earlier screen will have had ample time to reproduce in situ (as little as $24 \mathrm{~h}$ at $25^{\circ} \mathrm{C}$ ) generating a larger number of parasites which are less likely to be overlooked on subsequent screens.

\section{CONCLUSION}

Although the majority of compounds tested against Gyrodactylus spp. are reportedly effective (see Appendix 1), $100 \%$ efficacy has not been achieved without toxicity to hosts. Currently, the lack of comparative data makes the selection of a drug difficult. Leaving just one (hermaphrodite, viviparous) worm can be sufficient to initiate a new disease outbreak. For research projects, manual removal of skin gyrodactylids from small fish is an option; however, this is not feasible for gill parasites, larger hosts or for use in aquaculture. Further research into different treatments and their application on different species of parasite and host is necessary to combat the existing problems caused by Gyrodactylus spp. epizootics.

Acknowledgements. This work was supported by the Natural Environment Research Council, UK (NER/J/S/2002/00706).

\section{LITERATURE CITED}

Anttila P, Kuusela J, Koski P (2007) Disinfection of Gyrodactylus salaris by Virkon $\mathrm{S}$ and heat. Poster presentation at the 13th International Conference of Fish and Shellfish Diseases by the European Association of Fish Pathologists 17-21 September 2007, Grado, Italy. EAFP Abstract Book, p 334. Available at: http://eafp.org/eafp-information/ 2009/2/20/grado-2007-information-archived.html

Bakke TA, Harris PD, Cable J (2002) Host specificity dynamics: observations on gyrodactylid monogeneans. Int $\mathrm{J}$ Parasitol 32:281-308

Bakke TA, Cable J, Harris PD (2007) The biology of gyrodactylid monogeneans: the 'Russian-doll killers'. Adv Parasitol 64:161-376

> Bi SP, Yang XD, Zhang FP, Wang XL, Zou GW (2001) Analytical methodologies for aluminium speciation in environmental and biological samples - a review. Fresenius J Anal Chem 370:984-996

Birchall JD, Exley C, Chappell JS, Phillips MJ (1989) Acute toxicity of aluminium to fish eliminated in silicon-rich acid waters. Nature 338:146-148 
Buchmann K (1997) Salinity tolerance of Gyrodactylus derjavini from rainbow trout Oncorhynchus mykiss. Bull Eur Assoc Fish Pathol 17:123-125

Buchmann K, Kristensson RT (2003) Efficacy of sodium percarbonate and formaldehyde bath treatments against Gyrodactylus derjavini infestations of rainbow trout. N Am J Aquac 65:25-27

Buchmann K, Bresciani J, Jappe C (2004) Effects of formalin treament on epithelial structure and mucous cell densities in rainbow trout, Oncorhynchus mykiss (Walbaum), skin. J Fish Dis 27:99-104

Cable J, Harris PD (2002) Gyrodactylid developmental biology: historical review, current status and future trends. Int J Parasitol 32:255-280

Caboni P, Sherer TB, Zhang N, Taylor G, Na HM, Greenamyre JT, Casida JE (2004) Rotenone, deguelin, their metabolites and the rat model of Parkinson's disease. Chem Res Toxicol 17:1540-1548

Carter PKL (2003) The impact of low concentrations of cadmium on host-monogenean interactions. PhD dissertation, University of Stirling

Chansue N (2007) Effects of dried Indian almond leaf (Terminalia catappa L.) extract on monogenean parasites in goldfish (Carassius auratus). Wien Tieraerztl Monschr 94: 269-273

Costa LG (2006) Current issues in organophosphate toxicology. Clin Chim Acta 366:1-13

Crigel P, Losson B, Defour J (1995) Utilisation de la quinaldine, un anesthésique pour poissons, à des fins antiparasitaires. Ann Med Vet 139:343-348

Doll R (1993) Review: Alzheimer's disease and environmental aluminium. Age Ageing 22:138-153

Ekanem AP, Wang M, Simon JE, Obiekezie AI, Morah F (2004) In vivo and in vitro activities of the seed extract of Piper guineense Schum and Thonn against skin and gill monogenean parasites of goldfish (Carassius auratus auratus). Phytother Res 18:793-797

El-Khatib NRH (2003) Biological eradicaton of some parasitic diseases in fishes using Bacillus thuringiensis Agerin ${ }^{\circledR}$ product. Vet Med J Giza 51:19-28

European Council (1990) Regulation No 2377/90 of 26 June 1990 laying down a community procedure for the establishment of maximum residue limits for veterinary medicinal products in foodstuffs of animal origin. Off $\mathrm{J}$ Eur Union L 224:1-8

FishDoc (2008) Malachite green and formalin - a good general-purpose anti-parasite treatment. www.fishdoc. co.uk/treatments/malachite.htm (accessed 15 Dec 2008)

Gheorgiu C, Marcogliese DJ, Scott M (2005) Concentration-dependent effects of waterborne zinc on population dynamics of Gyrodactylus turnbulli (Monogenea) on isolated guppies (Poecilia reticulata). Parasitology 132:225-232

Goven BA, Amend DF (1982) Mebendazole/trichlorfon combination: a new anthelmintic for removing monogenetic trematodes from fish. J Fish Biol 20:373-378

Harris PD, Shinn AP, Cable J, Bakke TA, Bron J (2008) GyroDb: gyrodactylid monogeneans on the web. Trends Parasitol 24:109-111

IARC (International Agency for Research on Cancer) (2004) Monographs on the evaluation of carcinogenic risks to humans, Vol 88, formaldehyde, 2-butoxyethanol and 1tert-butoxy-2-propanol. IARC, Lyons

King TA, Harris PD, Cable J (2008) Long-term Gyrodactylus lomi infection on isolated juvenile chub, Leuciscus cephalus. J Parasitol 94(6):1426-1427

Kou GH, Liu CI, Liu CK (1988) Handbook of fish disease. Pig Research Institute Taiwan, Miaoli (in Chinese)
Kozlovskaya VI, Mayer FL (1984) Brain acetylcholinesterase and backbone collagen in fish intoxicated with organophophate pesticides. J Gt Lakes Res 10:261-266

> Lewis SD (1967) Prophylactic treatment of minnow hatchery ponds with paraformaldehyde to prevent epizootics of Gyrodactylus. Prog Fish-Cult 29:160-161

Liao C, Guo JJ, Su MS (1996) The use of chemicals in aquaculture in Taiwan, province of China. In: Arthur JR, Lavilla-Pitogo CR, Subasinghe RP (eds) Proceedings of the meeting on the use of chemicals in aquaculture in Asia, 20-22 May 1996, Tigbauan, Iloilo. SEAFDEC, Philippines, p 193-206

McGeer JC, Szedebinsky C, McDonald DG, Wood CM (2000) Effects of chronic sublethal exposure to waterborne $\mathrm{Cu}$, $\mathrm{Cd}$ or $\mathrm{Zn}$ in rainbow trout. 1: iono-regulatory disturbance and metabolic costs. Aquat Toxicol 50:231-234

Mo TA (1994) Status of Gyrodactylus salaris problems and research in Norway. In: Pike AW, Lewis JW (eds) Parasitic diseases of fish. Samara Publishing, Tresaith, p 43-56

Oh SJ, Park J, Lee MJ, Park SY, Lee JH, Choi K (2006) Ecological hazard assessment of major veterinary benzimidazoles: acute and chronic toxicities to aquatic microbes and invertebrates. Environ Toxicol Chem 25:2221-2226

Peña-Llopis S, Ferrando MD, Peña JB (2003) Fish tolerance to organophosphate-induced oxidative stress is dependent on the glutathione metabolism and enhanced by N-acetylcysteine. Aquat Toxicol 65:337-360

Pesticide Action Network UK (2001) Rotenone. Pesticides News 54:20-21

> Pettersen RA, Vøllestad LA, Flodmark LEW, Poléo ABS (2006) Effects of aqueous aluminium on four fish ectoparasites. Sci Total Environ 369:129-138

Poléo ABS (1995) Aluminium polymerization-a mechanism of acute toxicity of aqueous aluminium of fish. Aquat Toxicol 31:347-356

Poléo ABS, Schjolden J, Hansen H, Bakke TA, Mo TA, Rosseland BO, Lydersen E (2004) The effect of various metals on Gyrodactylus salaris (Platyhelminthes, Monogenea) infections in Atlantic salmon (Salmo salar). Parasitology 128:169-177

Rach JJ, Gaikowski MP, Ramsay RT (2000) Efficacy of hydrogen peroxide to control parasitic infestations on hatcheryreared fish. J Aquat Anim Health 12:267-273

Rintamäki-Kinnunen P, Valtonen ET (1996) Finnish salmon resistant to Gyrodactylus salaris: a long-term study at fish farms. Int J Parasitol 26:723-732

> Ross LG, Ward KMH, Ross B (1985) The effects of formalin, malachite green and suspended solids on the respiratory activity of rainbow trout, Salmo gairdneri Richardson. Aquac Res 16:129-138

Rowland ST, Nixon M, Landos M, Mifsud C, Read P, Boyd P (2006) Effects of formalin on water quality and parasitic monogeneans on silver perch (Bidyanus bidyanus Mitchell) in earthen ponds. Aquac Res 37:869-876

> Russo R, Curtis EW, Yanong RPE (2007) Preliminary investigations of hydrogen peroxide treatment of selected ornamental fishes and efficacy against external bacteria and parasites in green swordtails. J Aquat Anim Health 19:121-127

Sanchez JG, Speare DJ, Sims DE, Johnson GJ (1998) Morphometric assessment of epidermal and mucous-biofilm changes caused by exposure of trout to chloramine- $\mathrm{T}$ or formalin treatment. J Comp Pathol 118:81-87

> Santamarina MT, Tojo J, Ubeira FM, Quinteiro P, Sanmartín ML (1991) Anthelmintic treatment against Gyrodactylus sp. infecting rainbow trout Oncorhynchus mykiss. Dis Aquat Org 10:39-44 
Schmahl G (1993a) Treatment of fish parasites. 10. Effects of a new triazine derivative, HOE-092- $\mathrm{V}$, on Monogenea-a light and transmission electron-microscopy study. Parasitol Res 79:559-566

Schmahl G (1993b) Up to date chemotherapy against monogenea: a review. Bull Fr Pêche Piscic 328:74-81

Schmahl G, Mehlhorn H (1988) Treatment of fish parasites. 4. Effects of sym. triazinone (toltrazuril) on Monogenea. Parasitol Res 75:132-143

Schmahl G, Taraschewski H (1987) Treatment of fish parasites 2. Effects of praziquantel, niclosamide, levamisole, hydrochloride and metrifonate on Monogenea (Gyrodactylus aculeati and Diplozoon paradoxum). Parasitol Res 73:341-351

Schmahl G, Taraschewski H, Mehlhorn H (1989) Chemotherapy of fish parasites. Parasitol Res 75:503-511

Scholz T (1999) Parasites in feral and cultured fish. Vet Parasitol 84:317-355

Smith CE, Piper RG (1972) Pathological effects in formalin treated rainbow trout (Salmo gairdneri). J Fish Res Board Can 29:328-329

Soleng A, Bakke TA (1997) Salinity tolerance of Gyrodactylus salaris (Platyhelminthes, Monogenea): laboratory studies. Can J Fish Aquat Sci 54:1837-1864

Soleng A, Bakke TA, Hansen LP (1998) Potential for dispersal of Gyrodactylus salaris (Platyhelminthes, Monogenea) by sea-running stages of the Atlantic salmon (Salmo salar): field and laboratory studies. Can J Fish Aquat Sci 55: 507-514

Soleng A, Poléo ABS, Alstad NEW, Bakke TA (1999) Aqueous aluminium eliminates Gyrodactylus salaris (Platyhel- minthes, Monogenea) infections in Atlantic salmon. Parasitology 119:19-25

Soleng A, Poléo ABS, Bakke TA (2005) Toxicity of aqueous aluminium to the ectoparasitic monogenean Gyrodactylus salaris. Aquaculture 250:616-620

Speare DJ, Arsenault G, MacNair N, Powell MD (1997) Branchial lesions associated with intermittent formalin bath treatment of Atlantic salmon, Salmo salar L., and rainbow trout, Oncorhynchus mykiss (Walbaum). J Fish Dis 20:27-33

Srivastava S, Sinha R, Roy D (2004) Toxicological effects of malachite green. Aquat Toxicol 66:319-329

Steverding D, Morgan E, Tkaczynski P, Walder F, Tinsley R (2005) Effect of Australian tea tree oil on Gyrodactylus spp. infection of the three-spined stickleback Gasterosteus acuelatus. Dis Aquat Org 66:29-32

Tojo JL, Santamarina MT (1998) Oral pharmalogical treatments for parasitic diseases of rainbow trout Oncorhynchus mykiss. II: Gyrodactylus sp. Dis Aquat Org 33:187-193

Tojo J, Santamarina MT, Ubeira FM, Estevez J, Sanmartin ML (1992) Anthelmintic activity of benzimidazoles against Gyrodactylus sp. infecting rainbow trout Oncorhynchus mykiss. Dis Aquat Org 12:185-189

Tojo J, Santamarina MT, Ubeira FM, Leiro J, Sanmartin ML (1993a) Efficacy of antiprotozoal drugs against gyrodactylosis in rainbow trout (Oncorhynchus mykiss). Bull Eur Assoc Fish Pathol 13:79-82

Tojo J, Santamarina MT, Ubeira FM, Estevez J, Leiro J, Sanmartin ML (1993b) Efficacy of anthelmintic drugs against gyrodactylosis in rainbow trout (Oncorhynchus mykiss). Bull Eur Assoc Fish Pathol 13:45-48 


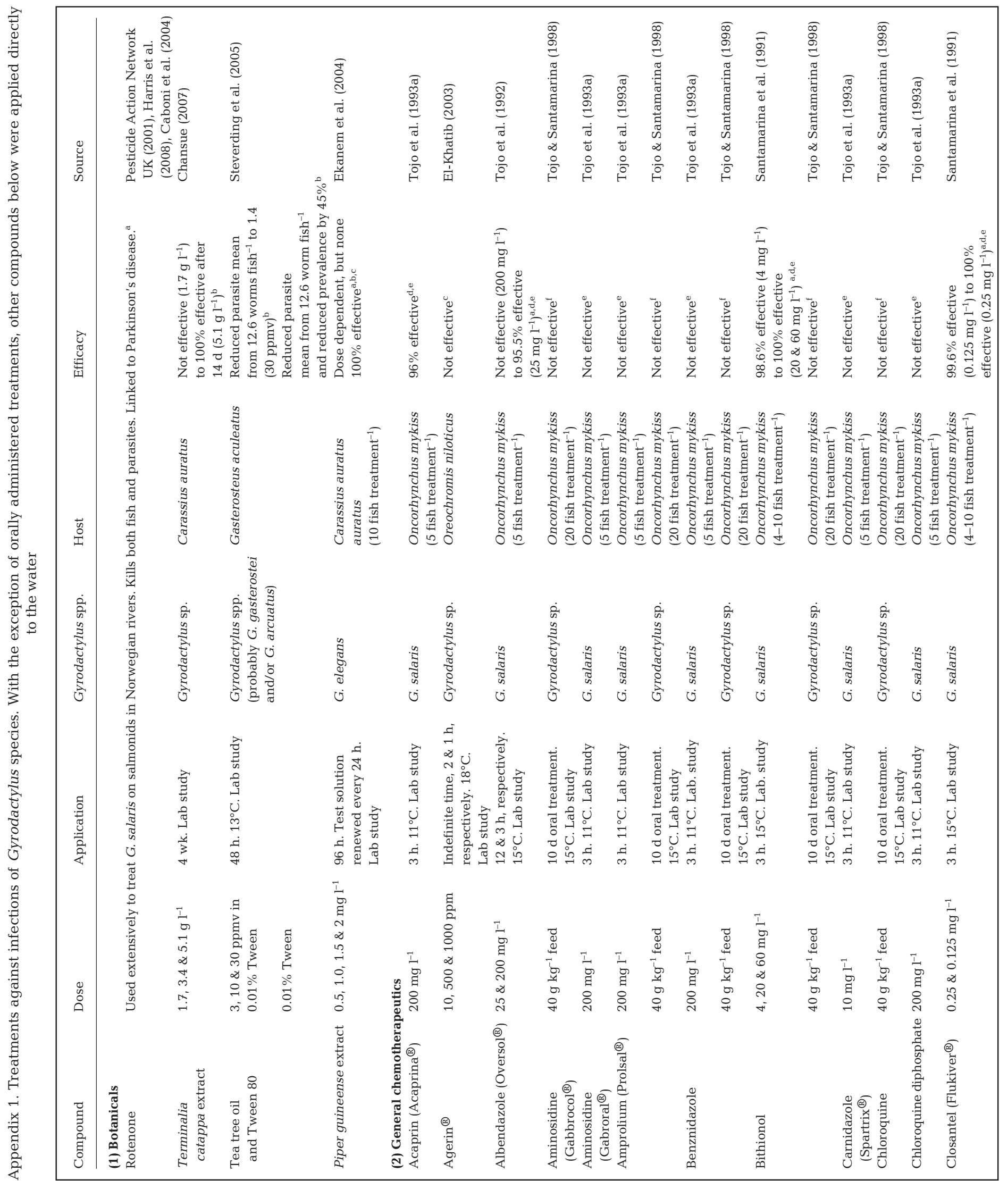




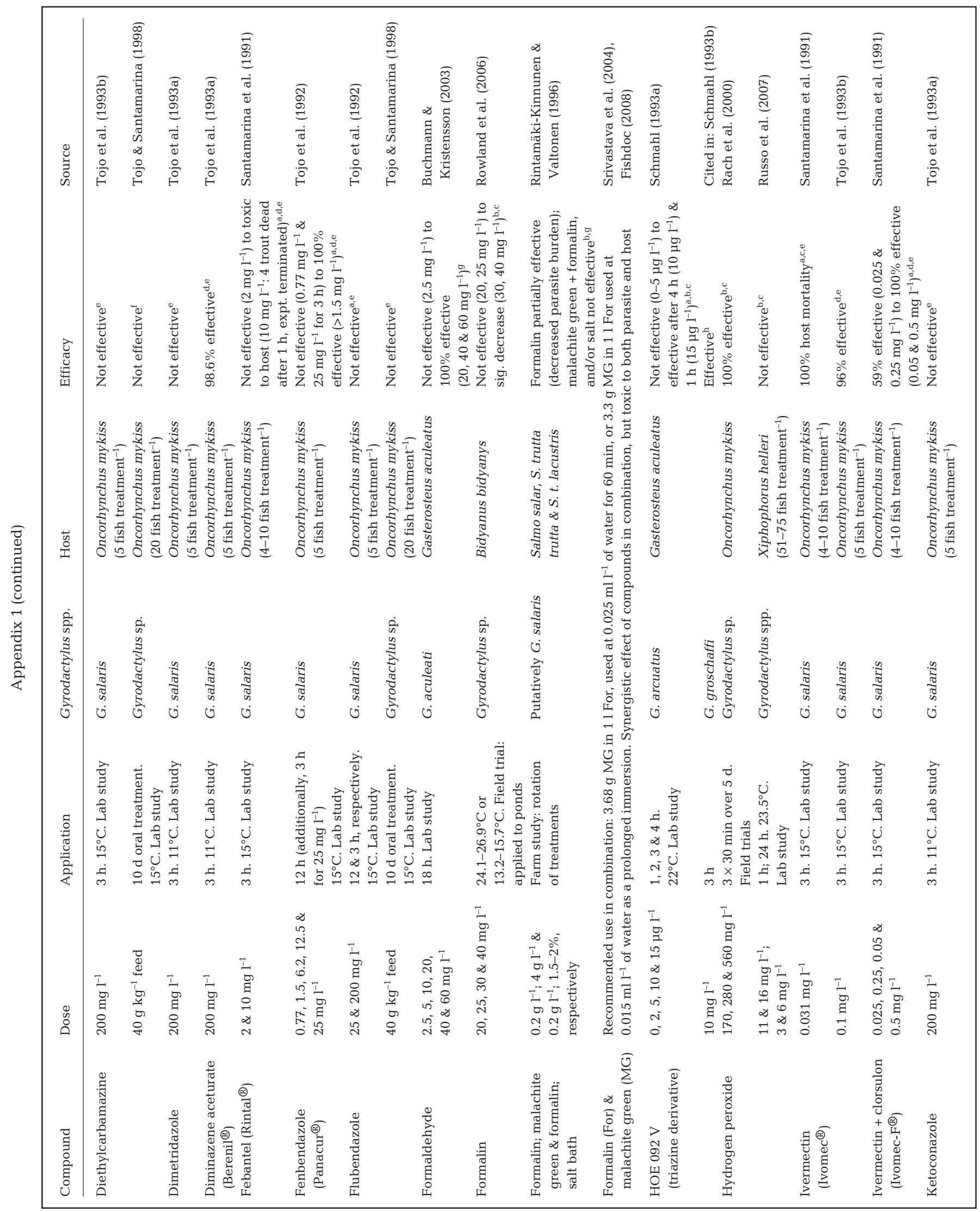




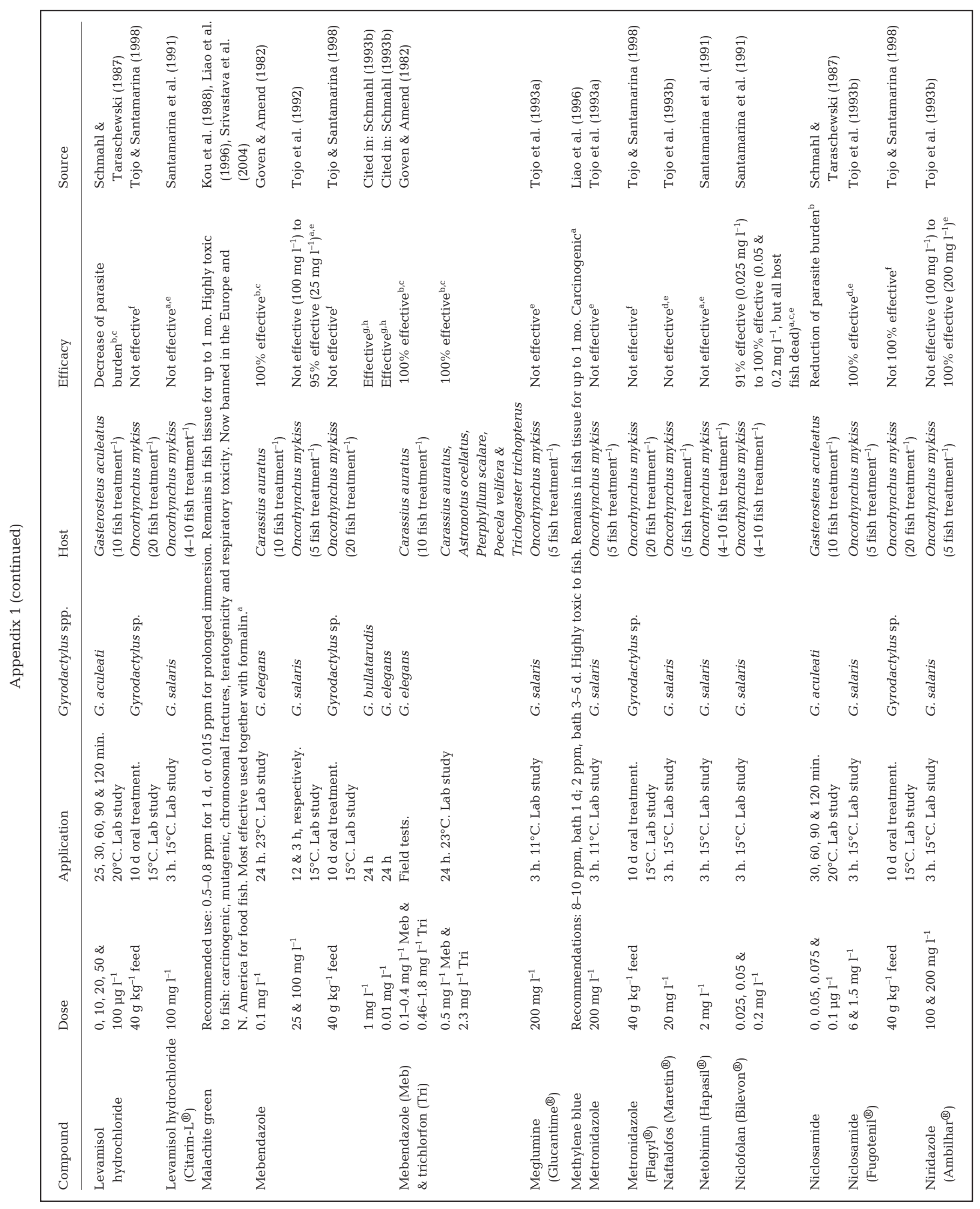




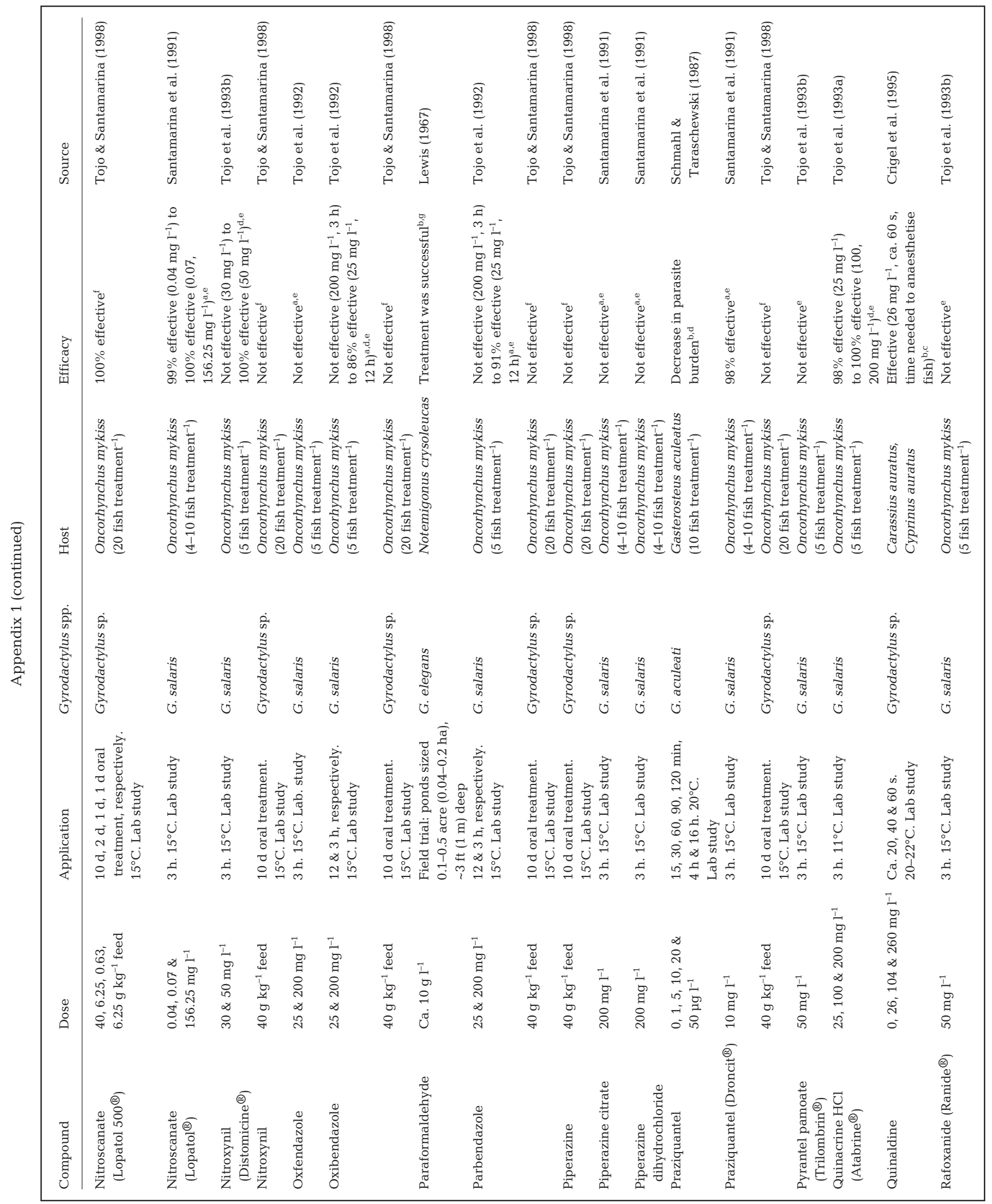




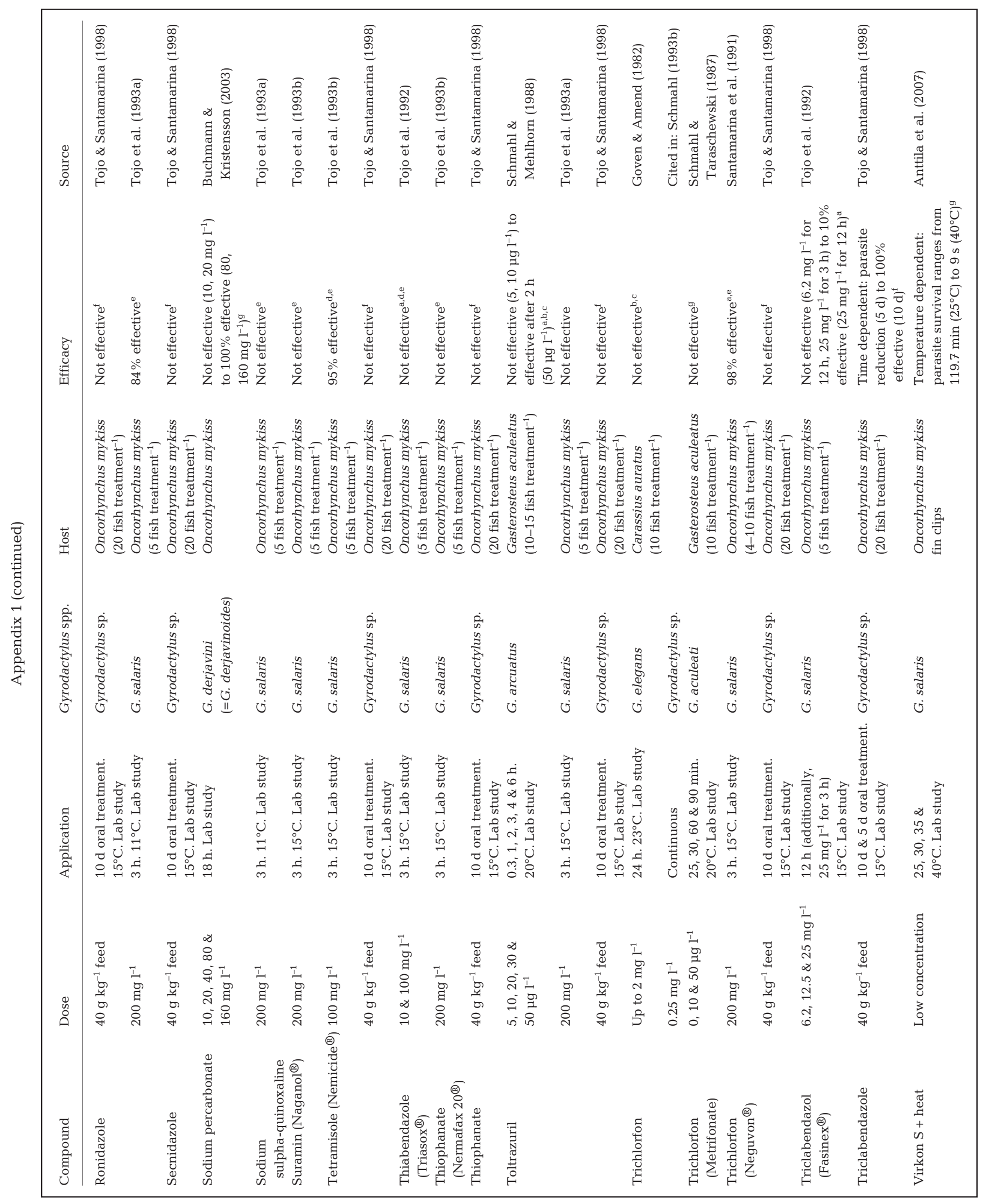




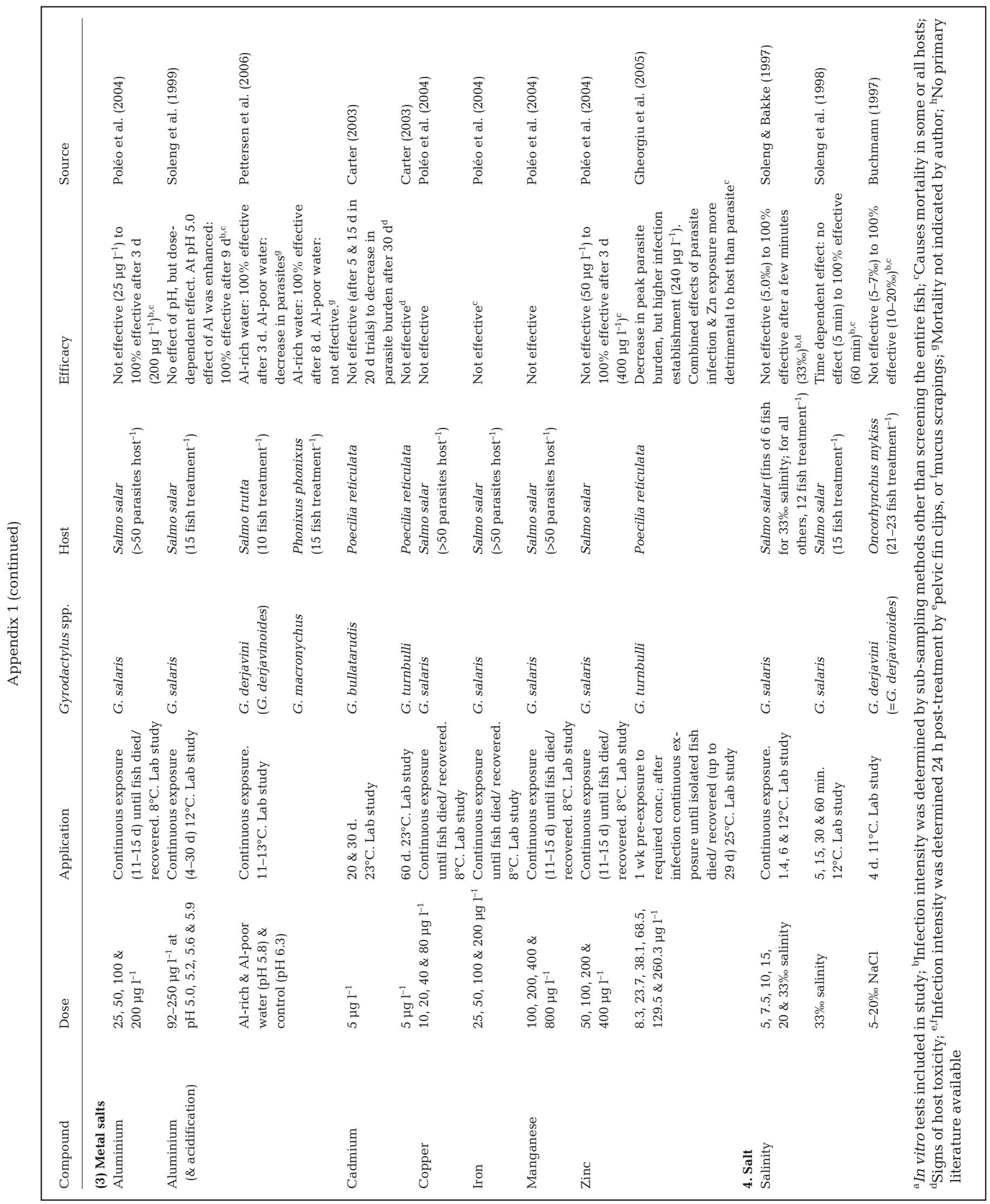

